\title{
Alae Nasi Activation in Preterm Infants during Oral Feeding
}

\author{
BRIAN J. M. TIMMS, JULIANN M. DIFIORE, RICHARD J. MARTIN, WALDEMAR A. CARLO, \\ AND MARTHA J. MILLER \\ Rainbow Babies' and Children's Hospital, Case Western Reserve University, Cleveland, Ohio 44106
}

\begin{abstract}
Preterm infants may demonstrate impaired ventilation during oral feeding with resultant hypoxemia and hypercarbia. This study was designed to determine whether infants activate a representative upper airway muscle, the ala nasi, in response to these ventilatory changes. Ten preterm infants (postconceptional age at study $35 \pm 4$ wk, weight $2.2 \pm 0.1 \mathrm{~kg}$ ) were studied during a control period, continuous feeding, subsequent intermittent feeding, and a period of nonnutritive sucking. Nasal airflow was measured with a pneumotachometer to quantify minute ventilation. The alae nasi electromyogram $\left(\mathrm{EMG}_{\mathrm{AN}}\right)$ was recorded with surface electrodes, and sucking pressure was detected by a catheter in the feeding nipple. End-tidal $\mathrm{CO}_{2}$ and $\mathrm{O}_{2}$ saturation were also recorded during each period. The percentage of breaths associated with $\mathrm{EMG}_{\mathrm{AN}}$ activity increased from $41 \pm 13 \%$ during the control period to $95 \pm 5 \%$ and $93 \pm 7 \%$ during continuous and intermittent sucking, respectively $(p<0.05)$. Eightyseven $\pm 5 \%$ of $\mathbf{E M G}_{\mathrm{AN}}$ activity occurred during inspiration. During continuous and intermittent sucking, the amplitude of $E M G_{A N}$ activity also increased $(6.8 \pm 5.2$ and $6.7 \pm 4.0$ arbitrary units/breath, respectively) compared with the control period $(2.4 \pm 2.8$ units/breath, $p<0.05)$. In association with the increase in $\mathbf{E M G}_{\mathrm{AN}}$ activity, $\mathrm{O}_{2}$ saturation fell from $98 \pm 1 \%$ in the control period to $95 \pm 1 \%$ during both continuous and intermittent feeding $(p<0.05)$, and minute ventilation fell from $274 \pm 80 \mathrm{~mL} / \mathrm{min} / \mathrm{kg}$ during the control period to $190 \pm 81$ and $208 \pm 57 \mathrm{~mL} / \mathrm{min} / \mathrm{kg}$ during continuous and intermittent feeding, respectively ( $p$ $<0.05$ ). We conclude that the preterm infant is able to activate the alae nasi while feeding. We speculate that activation of the upper airway muscles may contribute to reduction in upper airway resistance during feeding. (Pediatr Res 32: 679-682, 1992)
\end{abstract}

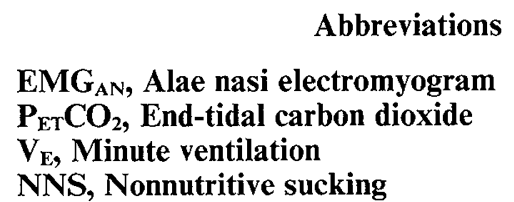

The preterm infant of less than 33-34 wk of gestation gradually develops adequate facility in oral feeding during the first weeks of life. The process of feeding challenges the infant to meet the simultaneous needs of both sustained ventilation and nutritive intake. The ability of the infant to modify the strategies of

Received February 13, 1992; accepted August 13, 1992.

Correspondence: Dr. Martha J. Miller, Division of Neonatology, Rainbow Babies' and Children's Hospital, 2074 Abington Rd., Cleveland, $\mathrm{OH} 44106$.

Supported by Grants HL 41814 and HL 25830. ventilation during feeding may be important, for previous work has shown that preterm infants may become hypoxemic and hypercarbic due to a decrease in $V_{E}$ that occurs during both continuous and intermittent sucking periods (1-3). The upper airway musculature has evolved to provide the infant with the ability to respond to the demands of both feeding and breathing.

The alae nasi are members of a group of dilator muscles (including posterior cricoarytenoid and genioglossus) that surround the airway from the nose to the glottis (4-7). Constriction of these muscles in phase with respiration can widen the upper airway and decrease resistance within this segment of the respiratory tract (4). Activation of these muscles may occur in phase with respiration in response to changing chemoreceptor drive or mechanoreceptor input $(8,9)$. We therefore hypothesized that activation of this network of muscles would occur during feeding in infancy. The present study was designed to determine whether preterm infants can effectively activate a representative member of this group, the alae nasi, in compensation for the ventilatory changes that occur during feeding.

\section{SUBJECTS AND METHODS}

The population consisted of 10 healthy preterm infants. Birth weight was $2.2 \pm 0.1 \mathrm{~kg}$ (mean $\pm \mathrm{SD}$ ), gestational age at birth 30 $\pm 3 \mathrm{wk}$, and postconceptional age at the time of study $35 \pm 4$ wk. All infants were breathing room air, and none was receiving treatment for apnea. The infants were all established on full bottle feedings for at least 2-3 d at the time of the study. Studies were performed in the neonatal physiology laboratory over a period of 45 to 90 min during a regularly scheduled feeding period. The study was approved by the Institutional Review Board and informed parental consent was obtained before patient enrollment.

$\mathrm{EMG}_{\mathrm{AN}}$ was recorded from two gold cup surface electrodes applied over the external nares (9). The electromyograms were amplified (Coulburn Fiber Optic Biological Preamplifiers, Lehigh Valley, PA), band-pass filtered from 30 to $1000 \mathrm{~Hz}$, full-wave rectified, and fed into a moving time averager (Charles Ward Enterprises, Ardmore, PA) with a time constant of $200 \mathrm{~ms}$. The amplitude of electromyogram activity was measured as the change from the baseline with every breath, expressed in arbitrary units, and averaged over 20 breaths. In addition, the percentage of breaths with alae nasi activity as well as the percentage of alae nasi activity coincident with inspiration was determined over the same epochs. Nasal airflow was measured with a nasal mask pneumotachograph (dead space $2 \mathrm{~mL}$, resistance $5.5 \mathrm{~cm} \mathrm{H}_{2} \mathrm{O}$ / $\mathrm{L} / \mathrm{s}$, linear to a flow of $8 \mathrm{~L} / \mathrm{min}$ ) connected to a Validyne MP45 Transducer $\left[ \pm 5 \mathrm{~cm} \mathrm{H}_{2} \mathrm{O}\right.$, Validyne, Northridge, $\left.\mathrm{CA}(10)\right]$. Flow was integrated to give tidal volume. Breaths with a tidal volume of $<1 \mathrm{~mL}$ were discounted for the purpose of calculation of $V_{E}$ $(1.8 \pm 2.2 \%$ of breaths $)$. $\mathrm{V}_{\mathrm{E}}$ was calculated from tidal volume and frequency. Continuous $\mathrm{P}_{\mathrm{ET}} \mathrm{CO}_{2}$ sampling was performed using an infrared $\mathrm{CO}_{2}$ analyzer (N-1000, Nellcor, Haywood, $\mathrm{CA}$ ). Plateaus of $\mathrm{P}_{\mathrm{ET}} \mathrm{CO}_{2}$ were considered acceptable if at least $0.4-$ 
$0.6 \mathrm{~s}$ in duration. Pulse oximetry was used to record $\mathrm{O}_{2}$ saturation and heart rate (Nellcor N-1000). All data were recorded simultaneously on a polygraph (model 2800 , Gould Inc., Cleveland, $\mathrm{OH})$ at $5 \mathrm{~mm} / \mathrm{s}$ and taped on an FM instrumentation recorder (model 3968A, Hewlett-Packard Co., San Diego, CA). During each individual study, $V_{E}$, the percentage of breaths associated with $\mathrm{EMG}_{\mathrm{AN}}$, amplitude of $\mathrm{EMG}_{\mathrm{AN}}, \mathrm{P}_{\mathrm{ETCO}}$, and $\mathrm{O}_{2}$ saturation were analyzed over epochs of 20 breaths during the control period and subsequent periods of continuous sucking, intermittent sucking, and NNS. To avoid bias, during the intermittent sucking phase, epochs that were analyzed contained both sucking and nonsucking periods. The mean and SD for each variable were then calculated for each epoch.

The infants were fed their regular formula through a specially designed nipple that allowed measurement of sucking pressure at the mouth while delivering milk flow from a reservoir that was maintained level with the infant's mouth to prevent gravitational delivery of milk flow, as previously described (1). This system also allowed control of nutrient delivery without removal of the nipple from the mouth, by regulation of flow through the tubing to the reservoir. After a 2-min control period, the nipple was introduced and the infant allowed to feed. After measurements were obtained during the control period, during continuous sucking, and during a subsequent period of intermittent sucking, the opportunity for NNS was offered by blocking the tube from the nipple to the feed reservoir. The volume of formula taken by the infant for the full feeding was recorded manually on the chart paper. The infants were nursed during the study, on an open bed, at an angle of approximately $45^{\circ}$ during the study, with the laboratory room temperature regulated to approximate the infant's neutral thermal environment.

Statistical analysis of data was performed by one-way analysis of variance for repeated measures and the Newman-Keuls procedure. Results in the text and table are expressed as mean \pm SD and a $p<0.05$ was required for significance.

\section{RESULTS}

All infants displayed a similar pattern of feeding when the nipple was introduced. Initially, a period of continuous sucking occurred that lasted for 20-30 s, associated with brief respiratory pauses of less than $2 \mathrm{~s}$ duration (Fig. 1). Continuous sucking was followed by periods of intermittent sucking associated with respiratory pauses alternating with respiratory bursts exceeding $4 \mathrm{~s}$ in duration (Fig. $2 A$ ). After continuous and intermittent sucking had occurred, the nutrient supply was blocked to provide the opportunity for NNS. All infants stopped nutritive sucking behavior within three to four sucks. Bursts of NNS then occurred every 5-10 s until the nutrient supply was restored (Fig. $2 B$ ). After milk flow resumed, the infants returned to continuous sucking for 20-30 s followed again by intermittent sucking.

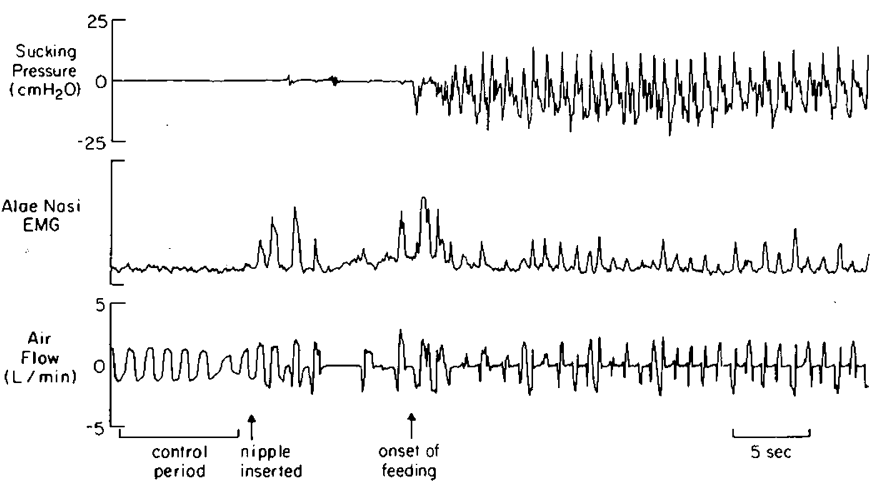

Fig. 1. A representative example of activation of $E M G_{A N}$ during feeding. After onset of continuous feeding, an increase in $E \mathrm{MG}_{\mathrm{AN}}$ activity and a decrease in $V_{E}$ were observed. Inspiration is upward on the airflow signal.



Fig. 2. $A$, An example of $\mathrm{EMG}_{\mathrm{AN}}$ during intermittent feeding. An increase in $\mathrm{EMG}_{\mathrm{AN}}$ activity occurred between sucking bursts when nasal airflow increased. $B$, An example of $\mathrm{EMG}_{\mathrm{AN}}$ during NNS. No significant increase in $\mathrm{EMG}_{\mathrm{AN}}$ occurred, either during NNS or between sucking bursts.

During the control period, $41 \pm 13 \%$ of inspirations were associated with $\mathrm{EMG}_{\mathrm{AN}}$ activity. The percentage of breaths with EMG $_{\text {AN }}$ activity increased to $95 \pm 5 \%$ and $93 \pm 7 \%$ during continuous and intermittent feeding, respectively (both $p<0.05$ compared to the control period). However, during NNS, only 49 $\pm 22 \%$ of inspirations were associated with $\mathrm{EMG}_{\mathrm{AN}}$ activity. During nutritive feeding, $87 \pm 5 \%$ of this alae nasi activity was coincident with inspiratory airflow of the breaths during feeding; EMG activity did not occur with sucking alone.

A significant increase in amplitude of $\mathrm{EMG}_{\mathrm{AN}}$ activity was also observed between the control period before feeding and the period of continuous sucking ( $2.4 \pm 2.8$ versus $6.8 \pm 5.2$ units/ breath, respectively, $p<0.05$ ) (Fig. 1, Table 1). An increased amplitude of $E M G_{A N}$ activity during bursts of respiration was also seen during intermittent sucking $[2.4 \pm 2.8$ versus $6.7 \pm 4.0$ units/breath for control versus intermittent sucking, respectively (Fig. 2A, Table 1)]. In contrast, no significant increase in amplitude of $\mathrm{EMG}_{\mathrm{AN}}$ activity occurred during NNS (Fig. $2 B$, Table 1).

When compared with the control period, a decrease in $\mathrm{O}_{2}$ saturation occurred during both continuous sucking and intermittent sucking $[98 \pm 1 \%$ versus $\pm 95 \pm 1 \%$ and $95 \pm 1 \%$, respectively, $p<0.05$ (Table 1 )]. $\mathrm{V}_{\mathrm{E}}$ also fell during continuous and intermittent sucking $[p<0.05$ (Table 1)]; however, no change in $\mathrm{P}_{\mathrm{Er}} \mathrm{CO}_{2}$ was detected over the same intervals.

\section{DISCUSSION}

The infant's ability to coordinate sucking and swallowing while breathing requires the maturation of complex mechanisms of upper airway muscle control. This "developmental milestone" is accomplished in most infants by 35-36 wk of postconceptional age. It is often not adequately developed in preterm infants, and its development may be further delayed in infants with bronchopulmonary dysplasia. Significant decreases in ventilation during feeding may result in periods of apnea, bradycardia, and/or 
Table 1. Effect of feeding on $E M G_{A N}$ activity and ventilation

\begin{tabular}{lccccc}
\hline & $\begin{array}{c}\text { \% of breaths associated } \\
\text { with } \mathrm{EMG}_{\mathrm{AN}} \text { activity }\end{array}$ & $\begin{array}{c}\text { Amplitude of } \mathrm{EMG}_{\mathrm{AN}} \\
\text { (arbitrary units/breath) }\end{array}$ & $\begin{array}{c}\mathrm{O}_{2} \text { saturation } \\
(\%)\end{array}$ & $\begin{array}{c}\mathrm{V}_{\mathrm{E}} \\
(\mathrm{mL} / \mathrm{min} / \mathrm{kg})\end{array}$ & $\begin{array}{c}\mathrm{P}_{\mathrm{ErCO}} \mathrm{CO}_{2} \\
(\mathrm{kPa})\end{array}$ \\
\hline Before feeding & $41 \pm 13$ & $2.4 \pm 2.8$ & $98 \pm 1$ & $274 \pm 80$ & $5.86 \pm 0.26$ \\
Continuous feeding & $95 \pm 5^{*}$ & $6.8 \pm 5.2^{*}$ & $95 \pm 1^{*}$ & $190 \pm 81^{*}$ & $5.86 \pm 0.53$ \\
Intermittent feeding & $93 \pm 7^{*}$ & $6.7 \pm 4.0^{*}$ & $95 \pm 1^{*}$ & $208 \pm 57^{*}$ & $5.99 \pm 0.53$ \\
NNS & $49 \pm 22$ & $4.3 \pm 3.6$ & $97 \pm 1$ & $291 \pm 84$ & $5.99 \pm 0.26$ \\
\hline
\end{tabular}

$* p<0.05$ when compared with control period before feeding.

cyanosis $(1,2,3,11,12)$. Previous studies have concentrated on the mechanisms of decreased $\mathrm{V}_{\mathrm{E}}$ during feeding, such as resistive loading of the airway, airway closure during swallowing, and the relationships between respiratory frequency and inspiratory and expiratory times $(13,14,15)$. In this study, we explored possible compensatory mechanisms by which $\mathrm{V}_{\mathrm{E}}$ may be maximized during feeding.

This study has confirmed previous findings with regard to the breathing and sucking pattern of preterm infants during feeding $(1,13,16)$. When compared with the control period, $V_{E}$ was significantly reduced during both continuous sucking and intermittent sucking in association with a significant reduction in $\mathrm{O}_{2}$ saturation. The cause of the reduction in $V_{E}$ during feeding is incompletely understood. It could arise as a direct consequence of the competing drives of feeding and breathing. Hypothetically, ventilatory drive is sustained during feeding by chemoreceptor input, whereas the voluntary and involuntary acts of sucking and swallowing continue until satiety is attained. It does appear that central chemoreceptor $\left(\mathrm{CO}_{2}\right)$ drive is depressed during feeding (17); thus, the infant may have a lower $V_{E}$ during feeding due to a depressed response to arterial $\mathrm{CO}_{2}$ tension. Obstruction to airflow may also occur, contributing to the decrease in $V_{E}(15)$. Another factor that could result in a low estimate of $V_{E}$ during feeding would be conversion to oronasal breathing (18). This study was not designed to detect oral breathing during feeding, so we cannot determine whether this factor could contribute to the decrease in $V_{E}$ that was observed. Because the infant's lips fit tightly around the nipple when sucking, significant oral breathing while feeding appears unlikely.

During feeding, muscles surrounding the upper airway and pharynx must synchronize the actions of sucking, swallowing, and respiration. This involves coordinated muscle contraction and relaxation resulting in dilation and constriction of specific segments of the upper airway during sucking and swallowing. In previous studies, we have shown that activation of the alae nasi muscles in sleeping preterm infants may decrease nasal airway resistance by up to $23 \%$ (4). In this study, we have demonstrated that a marked increase in both frequency and amplitude of inspiratory $E \mathrm{G}_{\mathrm{AN}}$ activity occurs during feeding, suggesting that a compensatory mechanism exists for improvement in ventilation by dilation of the upper airway during these periods of feeding.

Three potential stimuli could activate the alae nasi during feeding: hypercarbia (8), hypoxemia (19), and mechanoreceptor response within the airway itself (20). One paradox of feeding is that the decrease in $V_{E}$ that occurs is not accompanied by a large increase in $\mathrm{CO}_{2}$ tension in the blood. Indeed, in our study, no significant change in $\mathrm{P}_{\mathrm{ET}} \mathrm{CO}_{2}$ was observed between different periods of feeding. It is possible that the increase in $\mathrm{P}_{\mathrm{ET}} \mathrm{CO}_{2}$ was underestimated due to the limited numbers of plateaus in $\mathrm{P}_{\mathrm{ET}} \mathrm{CO}_{2}$ during feeding. In previous studies on nutritive feeding, Shivpuri et al. (1) observed an increase in $\mathrm{P}_{\mathrm{ET}} \mathrm{CO}_{2}$ from 5.19 to $5.59 \mathrm{kPa}$. Even such a modest change in $\mathrm{P}_{\mathrm{ET}} \mathrm{CO}_{2}$ would be below the threshold for activation of the alae nasi (21), and we speculate that a central chemoreceptor response to hypercarbia may not be the sole stimulus for alae nasi activation during feeding.

Mechanoreceptors that respond to subatmospheric pressure within the upper airway may also activate upper airway dilating muscles and inhibit the rate of diaphragmatic contraction $(20$, $22,23)$. It is conceivable that the subatmospheric pressure gen- erated in the pharynx during the breaths that occur between swallows could trigger this reflex response, resulting in inhibition of the diaphragm and activation of the alae nasi. Sucking itself appears unlikely to have triggered the $\mathrm{EMG}_{\mathrm{AN}}$, because $87 \pm 5 \%$ of the $\mathrm{EMG}_{\mathrm{AN}}$ activity was coincident with inspiratory airflow rather than sucking activity (Fig. 2).

Hypoxemia during feeding in preterm and term infants is well described $(1,2)$, and a decrease in $\mathrm{O}_{2}$ saturation during continuous and intermittent sucking was also demonstrated in this study. The dilator muscles of the upper airway, including the alae nasi, are activated by hypoxemia $(19,24,25)$, a response in large part attributed to the peripheral chemoreceptors. Hypoxemia therefore may be an additional stimulus for alae nasi activation during oral feeding. At the present time, it is not possible to determine which of the three potential factors (hypoxemia, hypercarbia, or mechanoreceptor stimulation) is most effective in activating the alae nasi during feeding.

If we assume that the alae nasi are representative of other upper airway dilator muscles, we may speculate that the entire network could function to increase airway caliber from the nose to the larynx during feeding. This would allow greater $V_{E}$ at the same level of respiratory drive and potentially decrease work of breathing. Both effects could benefit the infant, who is struggling to coordinate the simultaneous challenges of breathing and feeding.

\section{REFERENCES}

1. Shivpuri CR, Martin RJ, Carlo WA, Fanaroff AA 1983 Decreased ventilation in preterm infants during oral feeding. J Pediatr 103:285-289

2. Rosen CL, Glaze DG, Frost JD 1984 Hypoxemia associated with feeding in the preterm and full term neonate. Am J Dis Child 138:623-628

3. Mathew OP 1991 Breathing patterns of preterm infants during bottle feeding: role of milk flow. J Pediatr 119:960-965

4. Carlo WA, Martin RJ, Bruce EN, Strohl KP, Fanaroff AA 1983 Alae nasi activation (nasal flaring) decreased nasal resistance in preterm infants. Pediatrics 72:338-343

5. Carlo WA, Miller MJ, Martin RJ 1985 Differential response of respiratory muscles to airway occlusion in infants. J Appl Physiol 59:847-852

6. Barlett Jr D, Remmers JE, Gautier H 1973 Laryngeal regulation of respiratory airflow. Respir Physiol 18:194-204

7. Remmers JE, deGroot WJ, Sauerland EK, Anch AM 1978 Pathogenesis of upper airway occlusion during sleep. J Appl Physiol 44:931-938

8. Carlo WA, DiFiore JM 1990 Respiratory muscle responses to changes in chemoreceptor drive in infants. J Appl Physiol 63:1041-1047

9. Carlo WA, Martin RJ, Abboud EF, Bruce EN, Strohl KP 1983 Effect of sleep state and hypercapnia on alae nasi and diaphragm EMGs in preterm infants. J Appl Physiol 54:1590-1596

10. Anderson JV, Martin RJ, Lough MD, Martinez A 1982 An improved nasal mask pneumotachograph for measuring ventilation in infants. J Appl Physiol 53:1307-1309

11. Mathew OP 1988 Respiratory control during nipple feeding in preterm infants. Pediatr Pulmonol 5:220-224

12. 'Mathew OP 1991 Science of bottle feeding. J Pediatr 119:511-519

13. Wilson SL, Thach BT, Brouillette RT, Abu-Osba YK 1981 Coordination of breathing and swallowing in human infants. J Appl Physiol 50:851-858

14. Gryboski JD 1969 Suck and swallow in the preterm infant. Pediatrics 43:96102

15. Koenig JS, Davies AM, Thach BT 1990 Coordination of breathing, sucking, and swallowing during bottle feedings in human infants. $J$ Appl Physiol 69:1623-1629

16. Mathew OP Clark ML, Pronske ML, Luna-Solarzano HG, Peterson MD 1985 Breathing pattern and ventilation during oral feeding in term newborn infants. J Pediatr 106:810-813

17. Durand M, MacCallum M, Cates CB, Rigatto H, Chernick V 1981 Effect of feeding on the chemical control of breathing in the newborn infant. Pediatr Res 15:1509-1512 
18. Miller MJ, Martin RJ, Carlo WA, Fanaroff AA 1987 Oral breathing in response to nasal trauma in term infants. J Pediatr 111:899-901

19. Van Lunteren E, Strohl KP 1986 The muscles of the upper airways. Clin Chest Med 7:171-188

20. Mathew OP, Abu-Osba YK, Thach BT 1982 Influence of upper airway pressure changes on genioglossus muscle respiratory activity. J Appl Physiol 52:438444

21. Carlo WA, Martin RJ, DiFiore JM 1988 Differences in $\mathrm{CO}_{2}$ threshold of respiratory muscles in preterm infants. J Appl Physiol 65:2434-2439

22. Van Lunteren E, Van de Graff WB, Parker DM, Mitra J, Haxhiu MA, Strohl
KP, Cherniack NS 1984 Nasal and laryngeal reflex responses to negative upper airway pressure. J Appl Physiol 56:746-752

23. Van Lunteren E, Cherniack NS, Dick TE 1988 Upper airway pressure receptors alter expiratory muscle EMG and motor unit firing. J Appl Physiol 65:210 217

24. Weiner D, Mitra J, Salamone J, Cherniack NS 1982 Effect of chemical stimuli on nerves supplying upper airway muscles. J Appl Physiol 52:530-536

25. Martin RJ, Van Lunteran E, Haxhiu MA, Carlo WA 1990 Upper airway muscle and diaphragm responses to hypoxia in the piglet. J Appl Physio 68:672-677

\section{Announcements}

\section{Call for Abstracts}

The American Pediatric Society and The Society for Pediatric Research announce that the abstract deadline for the 1993 Annual Meeting (May 3-6, 1993, Sheraton Washington Hotel, Washington, DC) has been set as January 5, 1993. For further information contact: APS/SPR Association Headquarters, 141 Northwest Point Blvd., P.O. Box 675, Elk Grove Village, IL 60009-0675.

\section{8th Asian Congress of Pediatrics}

The 8th Asian Congress of Pediatrics will be held at the Hotel Ashok Samrat Complex, New Delhi, India, February 6-11, 1994. The theme of the congress will be "Child Health: Today, Not Tomorrow." For further information, contact Professor R. K. Puri, Secretary General, 8th Asian Congress of Pediatrics, Department of Pediatrics, Maulana Azad Medical College, New Delhi, 110 002, India, phone 91-11-3316031, fax $91-11-2283364$. 